(2) Open Access Full Text Article

SHORT REPORT

\title{
High prevalence of Helicobacter pylori infection in Malaysian Parkinson's disease patients
}

This article was published in the following Dove Press journal:

Journal of Parkinsonism and Restless Legs Syndrome

26 November 2013

Number of times this article has been viewed

\section{WY Nafisah'}

A Hamdi Najman'
R Hamizah'
S Azmin'
R Rabani'
SA Shah ${ }^{2}$
MI Norlinah'

'Department of Medicine, ${ }^{2}$ Department of Community Health, Universiti Kebangsaan Malaysia Medical Centre, Kuala Lumpur, Malaysia
Correspondence: WY Nafisah Department of Medicine, Universiti Kebangsaan Malaysia Medical Centre, Jalan Yaacob Latif, Cheras,

Kuala Lumpur 56000, Malaysia

$\mathrm{Tel}+60193212463$

Email nafisahyahya@gmail.com
Background: Studies have reported a higher prevalence of Helicobacter pylori (H. pylori) infection in Parkinson's disease.

Objectives: To determine the frequency of $H$. pylori in patients with Parkinson's disease compared to controls and its effect on symptom severity and quality of life.

Methods: A cross-sectional comparative study involving 29 Parkinson's disease patients and 23 controls. The ${ }^{13} \mathrm{C}$-urea breath test was used to diagnose H. pylori. Symptom severity and quality of life were assessed using the Unified Parkinson's Disease Rating Scale (UPDRS) and 39-item Parkinson's Disease Questionnaire (PDQ-39), respectively.

Results: The frequency of $H$. pylori infection was $48.3 \%$ in the Parkinson's disease group and $21.7 \%$ in controls $(P=0.048)$. This became more significant $(P=0.012)$ when we excluded relatives of $H$. pylori-positive patients from the control group. There was no association between Hoehn and Yahr stages, UPDRS and PDQ-39 scores, and H. pylori.

Conclusion: H. pylori infection is more prevalent in the Malaysian Parkinson's disease population compared to controls ( $48.3 \%$ versus $21.7 \%$ ). However, symptom severity and quality of life was not related to $H$. pylori infection.

Keywords: Parkinson's disease, Helicobacter pylori, prevalence, ${ }^{13} \mathrm{C}$-urea breath test

\section{Introduction}

An association between Helicobacter pylori (H. pylori) and Parkinson's disease (PD) was first noted when a high prevalence of duodenal and gastric ulcers was observed among PD patients. ${ }^{1}$ It was suggested that $H$. pylori might play a part in the biosynthesis of 1-methyl-4-phenyl-1,2,3,6-tetrahydropyridine (MPTP) or MPTP-like substances, which are directly neurotoxic to dopaminergic neurons. ${ }^{2}$ H. pylori has structural similarities to the plant seed cycad, which is believed to be neurotoxic. ${ }^{3}$ Cycad is known to cause amyotrophic lateral sclerosis/parkinsonism-dementia complex among populations in Guam ${ }^{4,5}$ and Japan's Kii Peninsula. ${ }^{6}$

Studies have shown that $H$. pylori infection leads to poorer motor function, ${ }^{7,8}$ and eradication leads to improvement in stride length. ${ }^{7}$ Eradication of $H$. pylori also correlated with a reduction in inflammatory markers, ${ }^{9,10}$ leading some authors to hypothesize that $H$. pylori infection leads to a chronic inflammatory process resulting in the destruction of dopaminergic neurons.

Studies in patients with PD have shown that levodopa absorption in the duodenum is affected by $H$. pylori ${ }^{11}$ Impaired gastric motility in advanced PD can also delay the transit and absorption of levodopa. One study showed that $H$. pylori-infected PD patients who received eradication therapy had consistently higher serum levodopa levels compared to 
untreated controls. The treated group had prolonged response to levodopa and fewer motor fluctuations. ${ }^{11}$ The authors concluded that $H$. pylori infection impairs absorption of levodopa, and eradication therapy is a simple way to enhance levodopa absorption and clinical response.

There are no studies on the prevalence of $H$. pylori infection among Malaysian PD patients, despite its high prevalence in our population. Given the possible therapeutic benefits of $H$. pylori eradication in PD, we set out to determine the prevalence of $H$. pylori infection among our PD patients compared to age-matched controls and its effect on motor function and quality of life.

\section{Materials and methods}

This was a cross-sectional comparative study. Consenting PD patients aged $\geq 18$ years were consecutively recruited from the outpatient clinic. Patients with secondary parkinsonism, Parkinson's plus, history of antibiotic use within 6 months, and proton pump-inhibitor or $\mathrm{H}_{2}$-antagonist use within 4 weeks of the urea breath test (UBT) and those who were unable to perform the UBT were excluded. An age- and sex-matched control group was recruited. Approval from the university research ethics committee was obtained prior to the study.

\section{Sample size}

The sample size for the study was calculated using the PS 3.0.7 (Power and Sample Size, 2009 release) Program by Dupont and Plummer from Vanderbilt University based on local data for probability of exposure among controls and cases. $^{12,13}$

\section{Study assessments}

\section{Baseline data}

Sociodemographic characteristics, previous antibiotic use, medical and medication history, and presence of gastrointestinal symptoms were recorded.

\section{PD-specific assessments}

PD severity was assessed using Hoehn and Yahr (H\&Y) staging and the Unified Parkinson's Disease Rating Scale (UPDRS). ${ }^{14}$ Quality of life was assessed using the 39-item Parkinson's Disease Questionnaire (PDQ-39). ${ }^{15}$

\section{UBT protocol}

Each subject was given $75 \mathrm{mg}$ of the infrared isotope analyzer, ${ }^{13} \mathrm{C}$ urea mixed in Tang ${ }^{\mathrm{TM}}$ orange drink. Breath samples were taken at $0,10,20$, and 30 minutes, and were analyzed using a nondispersive isotope-selective infrared spectrometer.
Interpretation of the results was based on IRIS software 2.3 for analysis of delta over baseline (DOB).

\section{DOB}

DOB is a measure of severity of $H$. pylori infection, as it correlates significantly with the total urease activity in the stomach. ${ }^{16,17}$ DOB has also been studied extensively and the value has been shown to be correlated with bacterial strain virulence, ${ }^{18}$ intensity of dyspeptic symptoms, ${ }^{19}$ and therapeutic efficacy. ${ }^{20} \mathrm{~A}$ DOB $>4.0$ was considered positive, while a $\mathrm{DOB}<2.5$ was considered negative. Values between 2.5 and 4.0 were considered positive if the subjects had taken antibiotics, proton-pump inhibitors, or $\mathrm{H}_{2}$ antagonists for 4-6 weeks prior to testing. Otherwise, patients were considered negative for $H$. pylori. The sensitivity and specificity of ${ }^{13} \mathrm{C}$-UBT are $98.3 \%$ and $98.6 \%$, respectively. ${ }^{21}$

\section{Statistical analysis}

All data were analyzed using SPSS version 19.0 (IBM, Armonk, NY, USA) for Windows. $P$-values of $<0.05$ were deemed significant.

\section{Results}

Of 57 eligible patients, only 29 were recruited, as 27 patients failed to show for the UBT and one had received recent antibiotic therapy. Twenty-three controls were recruited. Thirty-one males (59.6\%) and 21 females (40.4\%) were recruited. They consisted of 17 Malays (32.7\%), 30 Chinese $(57.7 \%)$, four Indians $(7.7 \%)$ and one Indonesian $(1.9 \%)$. The mean ages were $64.1 \pm 11.6$ years and $61.3 \pm 8.4$ years for the PD and control groups, respectively. The mean duration of PD from diagnosis was $5.8 \pm 4.7$ years. The demographic data of the study population are shown in Table 1.

\section{UBT}

We found significant differences in the frequency of $H$. pylori infection between PD patients and controls $(48.3 \%$ vs $21.7 \%, P=0.048)$. When we excluded subjects who were closely related to PD patients (one subject in the PD group and three in the control group) and those with recent or past $H$. pylori infections, our subanalysis achieved greater significance $(P=0.012)$ (Table 2$)$.

Comparative analysis between $H$. pylori-positive and -negative PD patients showed no significant differences in terms of H\&Y stages, duration of PD, PDQ-39, or UPDRS scores. When duration of PD was arbitrarily divided at 4 years, we observed that among those with $<4$ years of 
Table I Demographic data

\begin{tabular}{|c|c|c|c|}
\hline & $\begin{array}{l}\text { PD group } \\
(n=29)\end{array}$ & $\begin{array}{l}\text { Control group } \\
(n=23)\end{array}$ & $P$-value \\
\hline Age (years) & $64.1 \pm 11.6$ & $61.3 \pm 8.4$ & $0.325^{\theta}$ \\
\hline Height (m) & $1.59 \pm 0.07$ & $1.62 \pm 0.07$ & $0.082^{\theta}$ \\
\hline Weight (kg) & $64.04 \pm 9.53$ & $64.96 \pm 10.10$ & $0.742^{\ominus}$ \\
\hline BMI $\left(k g / m^{2}\right)$ & $25.38 \pm 3.40$ & $24.61 \pm 3.37$ & $0.435^{\ominus}$ \\
\hline \multicolumn{4}{|l|}{ Sex (\%) } \\
\hline Male & $16(55.2)$ & $15(65.2)$ & $0.463^{\rho}$ \\
\hline Female & $13(44.8)$ & $8(34.8)$ & \\
\hline \multicolumn{4}{|l|}{ Ethnicity (\%) } \\
\hline Malay & $7(24.1)$ & $10(43.5)$ & $0.260^{\xi}$ \\
\hline Chinese & $19(65.5)$ & II (47.8) & \\
\hline Indian & $3(10.3)$ & I (4.3) & \\
\hline Others & 0 & I (4.3) & \\
\hline \multicolumn{4}{|l|}{ Education (\%) } \\
\hline $\begin{array}{l}\text { Primary school } \\
\text { or less }\end{array}$ & $13(44.8)$ & $5(2 \mid .7)$ & $0.18^{\xi}$ \\
\hline Secondary school & 14 (48.3) & $13(56.5)$ & \\
\hline University/college & $2(6.9)$ & $4(17.4)$ & \\
\hline $\begin{array}{l}\text { Master's/ } \\
\text { postgraduate }\end{array}$ & $0(0.0)$ & I (4.3) & \\
\hline \multicolumn{4}{|l|}{ Employment (\%) } \\
\hline Professional & $3(10.3)$ & $2(8.7)$ & $0.23^{\xi}$ \\
\hline Nonprofessional & $7(24.1)$ & II (47.8) & \\
\hline $\begin{array}{l}\text { Unemployed/ } \\
\text { retired }\end{array}$ & $19(65.5)$ & $10(43.5)$ & \\
\hline \multicolumn{4}{|c|}{ Household income RM/month (\%) } \\
\hline$<\mathrm{I}, 000$ & $5(17.2)$ & $0(0)$ & $0.03^{\xi}$ \\
\hline $1,000-2,500$ & II (37.9) & $8(34.8)$ & \\
\hline $2,500-5,000$ & $10(34.5)$ & $6(26.1)$ & \\
\hline $5,000-10,000$ & $3(10.3)$ & $5(21.7)$ & \\
\hline$>10,000$ & $0(0)$ & $4(17.4)$ & \\
\hline
\end{tabular}

Notes: PPearson chi-squared; 'Fisher's exact test; ${ }^{\theta}$ independent $t$-test.

Abbreviations: PD, Parkinson's disease; BMI, body mass index; RM, Ringgit Malaysia.

disease, $35.7 \%$ were positive for $H$. pylori, while among those with disease duration of $\geq 4$ years, $60 \%$ were positive $(P=0.191)$ (Table 3).

\section{Levodopa and $H$. pylori status}

Total daily levodopa-dose requirements were divided into three groups ( $<400 \mathrm{mg}, 400-799 \mathrm{mg}$, and $\geq 800 \mathrm{mg}$ ) and

Table 2 Helicobacter pylori infection in Parkinson's disease (PD) versus control group

\begin{tabular}{clll}
\hline & $\begin{array}{l}\text { PD group, } \\
\mathbf{n = 2 9}(\%)\end{array}$ & $\begin{array}{l}\text { Control group, } \\
\mathbf{n = 2 3}(\%)\end{array}$ & P-value \\
\hline $\begin{array}{llll}\text { PD relatives included } \\
\text { H. pylori-positive }\end{array}$ & $14(48.3)$ & $5(21.7)$ & $0.048^{\rho}$ \\
$\begin{array}{c}\text { H. pylori-negative } \\
\text { PD relatives excluded }\end{array}$ & $15(51.7)$ & $18(78.3)$ & \\
H. pylori-positive & $14(50)$ & $3(15)$ & $0.012^{\rho}$ \\
H. pylori-negative & $14(50)$ & $17(85)$ & \\
\hline
\end{tabular}

Note: PPearson chi-squared $\left(\chi^{2}\right)$.

Abbreviation: H. pylori, Helicobacter pylori.
Table 3 Relationship between staging, quality of life and UPDRS scores with Helicobacter pylori status

\begin{tabular}{|c|c|c|c|}
\hline & $\begin{array}{l}\text { H. pylori- } \\
\text { positive, } \\
n=14\end{array}$ & $\begin{array}{l}H . \text { pylori- } \\
\text { negative, } \\
\mathrm{n}=15\end{array}$ & $P$-value \\
\hline \multicolumn{4}{|l|}{ Hoehn and Yahr, n (\%) } \\
\hline Stage I & I (7.I) & $2(13.3)$ & $0.466^{5}$ \\
\hline Stage 2 & II (78.6) & $9(60.0)$ & \\
\hline Stage 3 & $0(0)$ & $3(20.0)$ & \\
\hline Stage 4 & $2(14.3)$ & $2(6.7)$ & \\
\hline Duration of PD (years) & $5.5(3.1-10.8)$ & $3.0(2.5-10.0)$ & 0.174 \\
\hline \multicolumn{4}{|l|}{ PDQ39 } \\
\hline A: Mobility & $17(13.75-35.25)$ & $27(17.0-40.0)$ & 0.229 \\
\hline$B: A D L$ & $12(7.75-16.50)$ & $11.0(7.0-15.0)$ & 0.693 \\
\hline $\begin{array}{l}\text { C: Emotional } \\
\text { well-being }\end{array}$ & $1 \mathrm{I} .79 \pm 3.827$ & $|3.20 \pm 6.46|$ & $0.477^{\beta}$ \\
\hline D: Stigma & $8.5(4.0-14.25)$ & $6.0(4.0-14.0)$ & 0.807 \\
\hline E: Social support & $3.5(3.0-6.25)$ & $4.0(3.0-6.0)$ & 0.871 \\
\hline $\begin{array}{l}\text { F: Cognitive } \\
\text { impairment }\end{array}$ & $7.0(5.0-10.0)$ & $8.0(6.0-9.0)$ & 0.552 \\
\hline G: Communication & $4.5(3.0-8.0)$ & $4.0(3.0-6.0)$ & 0.457 \\
\hline $\begin{array}{l}\text { H: Bodily } \\
\text { discomfort }\end{array}$ & $4.5(3.0-7.0)$ & $3.0(3.0-5.0)$ & 0.202 \\
\hline \multicolumn{4}{|l|}{ UPDRS } \\
\hline $\begin{array}{l}\text { I: Mentation, } \\
\text { behavior, mood }\end{array}$ & $2.0(1.75-5.25)$ & $4.0(2.0-6.0)$ & 0.376 \\
\hline II: ADL & II.0(5.50-|17.0) & $10.0(6.0-19.0)$ & 0.983 \\
\hline $\begin{array}{l}\text { III: Motor } \\
\text { examination }\end{array}$ & $19.43 \pm 8.864$ & $19.20 \pm 11.66$ & $0.953^{\beta}$ \\
\hline $\begin{array}{l}\text { IV: Complications } \\
\text { to therapy }\end{array}$ & $3.0(2.0-5.0)$ & $3.0(1.0-4.0)$ & 0.307 \\
\hline
\end{tabular}

Notes: ' Fisher's exact test; ${ }^{\beta}$ mean \pm standard deviation, analyzed with paired $t$-test; all other data are expressed as medians (interquartile range) and were analyzed with Mann-Whitney U-test.

Abbreviations: UPDRS, Unified Parkinson's Disease Rating Scale; PDQ, Parkinson's Disease Questionnaire; ADL, activities of daily living; $H$. pylori, Helicobacter pylori.

analyzed for $H$. pylori positivity. There appeared to be more H. pylori-positive patients in the group with the highest levodopa requirement. However, these results were not statistically significant $(P=0.515)$.

\section{Discussion}

The prevalence of $H$. pylori varies widely. This was a crosssectional pilot study testing our hypothesis that $H$. pylori infection is higher in the PD population compared to non-PD population based on previously published data. ${ }^{12,13,22-24}$ Most studies reported rates between $40 \%$ and $93 \%$ in adults. ${ }^{25}$ Ethnicity is an important determinant, the lowest prevalence (11.9\%-29.2\%) being among Malays, followed by Chinese $(26.7 \%-57.5 \%)$ and Indians $(49.4 \%-52.3 \%))^{12,39-41}$ Our findings are therefore in keeping with locally published data.

Prevalence rates of $H$. pylori infection among PD patients in other countries were slightly higher than ours, ranging from $53.8 \%{ }^{13}$ to $64 \% .{ }^{22,23}$ This variation may be attributable 
to such factors as timing and location of the study and study population characteristics. ${ }^{25}$

One study, ${ }^{22}$ which used enzyme-linked immunosorbent assays to diagnose $H$. pylori, demonstrated that $70 \%$ of PD patients were positive for $H$. pylori compared to $36 \%$ of controls $(P<0.02)$. Serology has a specificity of $79 \%-90 \%$ and sensitivity of $76 \%-84 \% .{ }^{27,28}$ UBT has sensitivity and specificity $>95 \%{ }^{30,31}$ Patients who have been positive for H. pylori may remain seropositive for up to 4 years after eradication. ${ }^{26,29}$ Consequently, most studies using serology as a diagnostic test tend to overestimate $H$. pylori prevalence.

We noted H. pylori infection was higher in patients with a longer duration of $\mathrm{PD}$. Although this was not statistically significant, the possibility that PD patients may have characteristics that put them at risk of acquiring $H$. pylori infection should be considered. Possible reasons include poor gastric motility, ${ }^{32}$ levodopa, which has been shown to promote H. pylori growth, ${ }^{33}$ and worsening motor function leading to poor personal hygiene. It has been well demonstrated that H. pylori transmission is higher within close family members. ${ }^{34}$ When we took this into account and excluded the close family members from our sub-analysis, our findings gained further statistical significance (Table 2).

Our study did not demonstrate any relationship between H. pylori positivity and H\&Y stages, PDQ-39, or UPDRS scores. One possible explanation could be that higher UPDRS scores led to higher levodopa requirements, thus masking any true association. We observed higher requirements in our H. pylori-positive PD patients compared to their H. pylori-negative counterparts. However, this trend did not meet statistical significance. Lee et $\mathrm{al}^{13}$ and Borgohain et $\mathrm{al}^{24}$ likewise found no significant differences in UPDRS scores between $H$. pylori positive and negative patients. However, they observed significant difference in UPDRS scores after H. pylori eradication.

We noted a trend of increased levodopa-dose requirements with higher DOB levels. Lee et $\mathrm{al}^{13}$ and Pierantozzi et $\mathrm{al}^{23}$ demonstrated that $H$. pylori infection caused a reduction in levodopa absorption, which increased by $54 \%$ after eradication therapy. Studies have shown that levodopa may also encourage $H$. pylori growth. ${ }^{33,35}$ It has been demonstrated that $H$. pylori cultured in levodopa- and noradrenalin-rich media grew faster than $H$. pylori cultured in media resembling normal gastric milieu. This would suggest that H. pyloriinfected PD patients were less likely to achieve therapeutic levodopa levels, and would therefore have poorer control of their symptoms. Further studies need to be conducted to determine if this is true in vivo.
Another possible cause for a higher levodopa requirement in H. pylori-infected PD patients is the development of atrophic gastritis, which has been shown to have an association. ${ }^{36}$ There is no published research regarding the presence of atrophic gastritis in PD patients.

Treating asymptomatic $H$. pylori infection is not currently recommended. ${ }^{37,38,42}$ Screening is selected for those with symptoms or risk factors. For PD patients, however, it may be justified to screen for and treat $H$. pylori infection, as this may improve serum levodopa levels and motor function. More studies are needed to demonstrate a clear benefit of eradication therapy for PD patients before we can suggest H. pylori screening as part of treatment guidelines.

To summarize, we found that $H$. pylori infection was significantly higher in Malaysian PD patients compared to controls. There was a trend of a higher daily levodopa-dose requirements and severity of $H$. pylori infection. Our study found no association between presence of $H$. pylori infection and H\&Y stages, PDQ-39, or UPDRS scores.

\section{Disclosure}

The authors report no conflicts of interest in this work.

\section{References}

1. Strang RR. The association of gastro-duodenal ulceration and Parkinson's disease. Med J Aust. 1965;1(23):842-843.

2. Altschuler E. Gastric Helicobacter pylori infection as a cause of idiopathic Parkinson disease and non-arteric anterior optic ischemic neuropathy. Med Hypotheses. 1996;47(5):413-414.

3. Hirai Y, Haque M, Yoshida T, Yokota K, Yasuda T, Oguma K. Unique cholesteryl glucosides in Helicobacter pylori: composition and structural analysis. J Bacteriol. 1995;177(18):5327-5333.

4. Banack SA, Cox PA. Biomagnification of cycad neurotoxins in flying foxes: implications for ALS-PDC in Guam. Neurology. 2003;61(3): 387-389.

5. Iwami O, Niki Y, Watanabe T, Ikeda M. Motor neuron disease on the Kii Peninsula of Japan: cycad exposure. Neuroepidemiology. 1993;12(6): 307-312.

6. Banack SA, Nunn PB, Cheng R, Bradley WG. Washed cycad flour contains $\beta$-N-methyl amino-L-alanine and may explain parkinsonism symptoms. Ann Neurol. 2011;69(2):423.

7. Bjarnason IT, Charlett A, Dobbs RJ, et al. Role of chronic infection and inflammation in the gastrointestinal tract in the etiology and pathogenesis of idiopathic parkinsonism. Part 2: Response of facets of clinical idiopathic parkinsonism to Helicobacter pylori eradication. A randomized, double-blind, placebo-controlled efficacy study. Helicobacter. 2005;10(4):276-287.

8. Dobbs SM, Dobbs RJ, Weller C, et al. Differential effect of Helicobacter pylori eradication on time-trends in brady/hypokinesia and rigidity in idiopathic parkinsonism. Helicobacter. 2010;15(4):279-294.

9. Tansey MG, Goldberg MS. Neuroinflammation in Parkinson's disease: its role in neuronal death and implications for therapeutic intervention. Neurobiol Dis. 2010;37(3):510-518.

10. Tansey MG, McCoy MK, Frank-Cannon TC. Neuroinflammatory mechanisms in Parkinson's disease: potential environmental triggers, pathways, and targets for early therapeutic intervention. Exp Neurol. 2007;208(1):1-25. 
11. Pierantozzi M, Pietroiusti A, Galante A, et al. Helicobacter pyloriinduced reduction of acute levodopa absorption in Parkinson's disease patients. Ann Neurol. 2001;50(5):686-687.

12. Sasidharan S, Uyub AM. Prevalence of Helicobacter pylori infection among asymptomatic healthy blood donors in Northern Peninsular Malaysia. Trans R Soc Trop Med Hyg. 2009;103(4):395-398.

13. Lee WY, Yoon WT, Shin HY, Jeon SH, Rhee PL. Helicobacter pylori infection and motor fluctuations in patients with Parkinson's disease. Mov Disord. 2008;23(12):1696-1700.

14. Mitchell SL, Harper DW, Lau A, Bhalla R. Patterns of outcome measurement in Parkinson's disease clinical trials. Neuroepidemiology. 2000;19(2):100-108.

15. Jenkinson C, Fitzpatrick R, Peto V, Greenhall R, Hyman N. The Parkinson's Disease Questionnaire (PDQ-39): development and validation of a Parkinson's disease summary index score. Age Ageing. 1997;26(5):353-357.

16. Perri F, Clemente R, Pastore M, et al. The 13C-urea breath test as a predictor of intragastric bacterial load and severity of Helicobacter pylori gastritis. Scand J Clin Lab Invest. 1998;58(1):19-27.

17. Zagari RM, Pozzato P, Martuzzi C, et al. 13C-urea breath test to assess Helicobacter pylori bacterial load. Helicobacter. 2005;10(6): 615-619.

18. Zullo A, Sanchez-Mete L, Hassan C, et al. Helicobacter pylori density and cagA status in cirrhotic patients: a case-control study. J Gastroenterol Hepatol. 2004;19(10):1174-1178.

19. Franceschi F, Armuzzi A, Cremonini F, et al. Delta13CO excretion and expression of dyspeptic symptoms in patients evaluated for Helicobacter pylori infection by [13C] urea breath test. Dig Dis Sci. 2002;47(4): 804-808.

20. Sheu BS, Yang HB, Su IJ, Shiesh SC, Chi CH, Lin XZ. Bacterial density of Helicobacter pylori predicts the success of triple therapy in bleeding duodenal ulcer. Gastrointest Endosc. 1996;44(6):683-688.

21. Kalach N, Briet F, Raymond J, et al. The 13carbon urea breath test for the noninvasive detection of Helicobacter pylori in children: comparison with culture and determination of minimum analysis requirements. J Pediatr Gastroenterol Nutr. 1998;26(3):291-296.

22. Charlett A, Dobbs RJ, Dobbs SM, Weller C, Brady P, Peterson DW. Parkinsonism: siblings share Helicobacter pylori seropositivity and facets of syndrome. Acta Neurol Scand. 1999;99(1):26-35.

23. Pierantozzi M, Pietroiusti A, Brusa L, et al. Helicobacter pylori eradication and 1-dopa absorption in patients with PD and motor fluctuations. Neurology. 2006;66(12):1824-1829.

24. Borgohain R, Reddy VC, Meenaa AK, Jabeen SA. Helicobacter pylori eradication improves treatment response in advanced Parkinson's disease. Ann Indian Acad Neurol. 2008;11 Suppl 2:S138.

25. Pounder RE, Ng D. The prevalence of Helicobacter pylori infection in different countries. Aliment Pharmacol Ther. 1995;9 Suppl 2: 33-39.

26. Bode G, Hoffmeister A, Koenig W, Brenner H, Rothenbacher D. Characteristics of differences in Helicobacter pylori serology and 13Curea breath-testing in an asymptomatic sample of blood donors. Scand J Clin Lab Invest. 2001;61(8):603-608.
27. Chey WD, Murthy U, Shaw S, et al. A comparison of three fingerstick, whole blood antibody tests for Helicobacter pylori infection: a United States, multicenter trial. Am J Gastroenterol. 1999;94(6): 1512-1516.

28. Tham TC, McLaughlin N, Hughes DF, et al. Possible role of Helicobacter pylori serology in reducing endoscopy workload. Postgrad Med J. 1994;70(829):809-812.

29. Cutler AF, Prasad VM, Santogade P. Four-year trends in Helicobacter pylori IgG serology following successful eradication. Am J Med. 1998;105(1):18-20.

30. Lee HS, Gwee KA, Teng LY, et al. Validation of [13C] urea breath test for Helicobacter pylori using a simple gas chromatograph-mass selective detector. Eur J Gastroenterol Hepatol. 1998;10(7):569-572.

31. Hoang TT, Rehnberg AS, Wheeldon TU, et al. Comparison of the performance of serological kits for Helicobacter pylori infection with European and Asian study populations. Clin Microbiol Infect. 2006;12(11):1112-1117.

32. Soykan I, Lin Z, Bennett JP, McCallum RW. Gastric myoelectrical activity in patients with Parkinson's disease: evidence of a primary gastric abnormality. Dig Dis Sci. 1999;44(5):927-931.

33. Freestone PP, Lyte M. Microbial endocrinology: experimental design issues in the study of interkingdom signalling in infectious disease. Adv Appl Microbiol. 2008;64:75-105.

34. Nguyen VB, Nguyan GK, Phung DC, et al. Intra-familial transmission of Helicobacter pylori infection in children of households with multiple generations in Vietnam. Eur J Epidemiol. 2006;21(6):459-463.

35. Lyte M. Microbial endocrinology as a basis for improved L-DOPA bioavailability in Parkinson's patients treated for Helicobacter pylori. Med Hypotheses. 2010;74(5):895-897.

36. Kokkola A, Sipponen P, Rautelin H, et al. The effect of Helicobacter pylori eradication on the natural course of atrophic gastritis with dysplasia. Aliment Pharmacol Ther. 2002;16(3):515-520.

37. Fock KM, Katelaris P, Sugano K, et al. Second Asia-Pacific Consensus Guidelines for Helicobacter pylori infection. J Gastroenterol Hepatol. 2009;24(10):1587-1600.

38. Rubin G, Meineche-Schmidt V, Roberts A, de Wit N. The use of consensus to develop guidelines for the management of Helicobacter pylori infection in primary care. European Society for Primary Care Gastroenterology. Fam Pract. 2000;17 Suppl 2:S21-S26.

39. Goh KL. Epidemiology of Helicobacter pylori infection in Malaysiaobservations in a multiracial Asian population. Med J Malaysia. 2009;64(3):187-192.

40. Kaur G, Naing NN. Prevalence And Ethnic Distribution of Helicobacter Pylori Infection Among Endoscoped Patients In North Eastern Peninsular Malaysia. Malaysian Journal of Medical Sciences. 2003;10(2):66-70.

41. Goh KL, Parasakthi N. The racial cohort phenomenon: seroepidemiology of Helicobacter pylori infection in a multiracial South-East Asian country. Eur J Gastroenterol Hepatol. 2001;13(2):177-183.

42. Rees K, Stowe R, Patel S, et al. Helicobacter pylori eradication for Parkinson's disease. Cochrane Database Syst Rev. 2011;(11) CD008453.
Journal of Parkinsonism \& Restless Legs Syndrome

\section{Publish your work in this journal}

Journal of Parkinsonism and Restless Legs Syndrome is an online, open access, peer-reviewed journal. The journal publishes review articles, historical reviews, original research articles, case reports, letters to the editor, clinical teaching cases, neuroradiology highlights, neuropathology highlights, neuropsychiatry highlights, autobiographies, conference

\section{Dovepress}

proceedings, abstracts and book reviews. The manuscript management system is completely online and includes a very quick and fair peerreview system, which is all easy to use. Visit http://www.dovepress.com testimonials.php to read real quotes from published authors. 